\title{
Surfaces
}

\section{THE MEDIA AND THE WAR}

\section{Samuel Weber}

Volume 1, 1991

URI : https://id.erudit.org/iderudit/1065261ar

DOI : https://doi.org/10.7202/1065261ar

Aller au sommaire du numéro

Éditeur(s)

Les Presses de l’Université de Montréal

\section{ISSN}

1188-2492 (imprimé)

1200-5320 (numérique)

Découvrir la revue

\section{Citer cet article}

Weber, S. (1991). THE MEDIA AND THE WAR. Surfaces, 1.

https://doi.org/10.7202/1065261ar

\section{Résumé de l'article}

Une critique de la nature de la représentation de la guerre du Golf dans les médias de masse américains.
Copyright @ C Samuel Weber, 1991

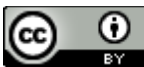

Ce document est protégé par la loi sur le droit d'auteur. L'utilisation des services d'Érudit (y compris la reproduction) est assujettie à sa politique d'utilisation que vous pouvez consulter en ligne.

https://apropos.erudit.org/fr/usagers/politique-dutilisation/ 


\section{THE MEDIA AND}

\section{THE WAR}

$\underline{\text { Samuel Weber }}$

\section{ABSTRACT}

A critique of the nature of the representation of the Gulf War in the American mass media.

\section{RÉSUMÉ}

Une critique de la nature de la représentation de la guerre du Golf dans les médias de masse américains.

Q. $<<$ Sir, I'm struck by -- I know these are serious topics, but I'm struck by how somber you feel, you seem, at least here. And I'm wondering, aren't these great days? Is this the highlight of your life? And how does this compare to being plucked out of the ocean a couple of years back? >>

A. $<<$ Well, to be very honest with you, I haven't yet felt this wonderful euphoric feeling that many of the American people feel. I'm beginning to. I feel much better about it today than I did yesterday. But I think it's that I want to see an end. You mention World War II. There was a definitive end to that conflict. [...] I just need a little more time to sort out in my mind how we -- I can say to the American people, it's over, finally. Last " $t$ " is crossed, last "i" is dotted. $>>$

President Bush, Presidential Press Conference, 
cited in the NY Times, March 2, 1991

[[section] $]$

$<<$ The Prince is the paradigm of the melancholic. Nothing demonstrates the frailty of creation more drastically than the fact that even he is subjected to it. $>>$

Walter Benjamin,

The Origins of the German Mourning Play

\section{Live Coverage: The End in Sight}

I want to begin my remarks today with some general considerations on the media, and then slowly work my way toward the particular question of its relation to the war in the Persian Gulf. First of all, in order to situate what I have to say, I think we should

/pp 5-6/

keep in mind that the media, both in its structure and in its effects, are extremely complicated, diverse and perhaps most important, extremely contradictory, and that therefore I very much doubt that any simple, onetrack explanation or interpretation of them is going to be very helpful. For instance, the media, and in particular television --which will be my main focus today-- play an enormous, perhaps even determining role in the way people conceive of reality. And yet, at the same time, the reality that the media present has a strangely unreal aspect to it, it is de-realized in certain essential aspects. Related to this contradiction, one can also argue that people depend upon the media for their orientation, perhaps even for their stability, and yet at the same time this function of reassurance seems structurally linked to its opposite, the production of anxiety. A final instance of the contradictory structure and effects of the media: the media overcomes distance, it would seem, and in this sense brings peoples and places together; and yet, at the very same time, it separates them all the more effectively: one would be tempted to say that television brings people and places together only in order to better keep them apart.

It was this kind of contradiction that the German thinker, Martin Heidegger, sought to describe as far back as 1947, in a lecture entitled "The Thing", which begins as follows: 
All distances in time and space are shrinking. What previously took weeks and months of travel, is now reached by plane overnight. What formerly became known only after years, if at all, is experienced today through radio instantaneously, on the hour. [...] Distant sites of the most ancient cultures are shown on film as though they were standing right now in the midst of local traffic. Moreover, film attests to what it shows by showing the recording camera and its crew at work. The culmination of this elimination of every possibility of distance (Ferne) is attained by television, which will soon pervade and dominate the whole mechanism of communication.

/pp 6-7/

Man puts the largest expanses behind him in the shortest time. He puts the greatest distances behind himself and thereby brings everything before him at the shortest range (auf die kleinste Entfernung).

Yet this rushed abolition of all remoteness brings no closeness; for closeness does not consist in the reduction of distance. What is least removed from us in terms of expanse, through the image in film or through sound in radio, can still remain remote. What in terms of expanse is unimaginably far removed, can be very close to us.

And Heidegger concludes these observations with a series of questions:

What is closeness if it fails to come about despite the reduction of the longest distances to the shortest intervals? [...] What is happening here when, as a result of the abolition of great distances, everything is equally far and equally near? What is this uniformity in which everything is neither far nor near --is, as it were, without distance? (The Thing, Poetry, Language, Thought, 165-166)

What I want to suggest, now, is that the kinds of contradictions Heidegger describes and the questions that he raises can be extremely helpful in understanding the way in which the media work, and in particular, in understanding the very particular and intimate relationship between the media and war: war in general, and the war against Iraq in particular.

In order to illustrate this assertion, which I offer as a kind of working hypothesis, let me turn to an instance from the recent televised reporting of the war, one that I imagine that many of you will have seen, not once but many times. It is an image, or rather sequence of images that both confirms the general gist of Heidegger's observations, and at the same time allows us to develop some of their implications in a concrete manner. I am thinking of the /pp 7-8/ 
televised images with which the American military sought to illustrate the precision nature of its bombing attacks, their "pin-point accuracy". It is the sequence of images taken from a television camera situated in the nose of a missile, as it homes in on its target, an Iraqi building. First of all, I want to call attention to the tendency of the media, mentioned by Heidegger, to demonstrate its authority and power by displaying its own technical apparatus at work. The most familiar example of this is the television control room, consisting of banks of television screens and the apparatus to control them, that serves as a backdrop and setting for many news programs: what the scene seems to say, by implication, is that the eyes of television are everywhere, they are multiple: they are the eyes through which the viewer sees, but also the eyes that are directed at the viewers themselves. Now, the pictures sent back by the missile on its way to impact do not display the camera, but they suggest something else: namely, that the television camera is not a mere observer of something going on independently of it. Rather, it is an integral and essential part of the military action itself. The television camera is part of the system of guidance and evaluation through which missiles are directed at targets, hits or misses confirmed, and finally, future strikes determined. That is the first point to be made: the television camera and its technology is anything but a mere voyeur in the enormous destructive activity taking place.

But --and now we begin to engage those contradictions of which I spoke at the outset-- the television images are at the same time part of an extremely and highly charged voyeuristic experienced. What does that experience consist in? First of all, the target is sighted, fixed at the center of the crosshairs: the television camera is of course a gun-sight. The exact point of impact is determined, and all possible variations are reduced to a minimum as the image grows every larger, ever more discernible as a recognizable object: a building, walls, doors etc. The object is thus brought closer and closer, becomes more and more recognizable, more and more familiar, until... until the screen goes blank, or rather, turns black with a thousand points of light all vibrating in /pp 8-9/

order as it were to underscore the sudden disappearance of the image, the blackness of the screen. The target has been hit, the object has been destroyed, what we have seen is no more. The mission is presumably accomplished. But what does such an accomplished mission mean in this particular case? Visually, the viewer has a bird or bomb's eye view of the action, which focuses upon shapes that are at television first distant and indistinct, and which gradually draw closer, become more discernible until they are right upon us, until that is the camera and its object become one, at which point the image disappears, the screen goes almost blank, or rather black, and we are back to the framework provided by the media: i.e. either the television control room, or the military press conference, or the familiar face of the television reporter.

What going on in this example, and why do I say that it epitomizes and condenses much of the function of the media, in general, and in respect to 
the War in particular? What is going on is first of all the reduction of distance, and at the same time, its maximization. The distance to the image, the target, is reduced and eliminated, and with it, the target-image is itself eliminated, vanishes from the screen. At the same time, everything is more distant than ever before. For we "know", or think we know, that the target has been destroyed, and with it, everything that we have not seen: all the things and people presumably behind those walls. At the same time, we, who have followed this elimination of distance through the eyes of the camera, which is also eyes of the missile, we are still whole, safe and sane in our homes. We are exhilarated at the sight of such power and control, we are relieved to be still in one piece, but we cannot entirely forget what we have seen without seeing it: enormous destruction and death. We are in one piece but others are not. This gnawing suspicion is what makes us relieved to be returned to the familiar and reassuring framework provided by what is aptly called media "coverage"; something is indeed being "covered", the way a "carpet" covers a floor, or the way "carpet bombings" cover an area. What is being covered is ultimately that which technology has always potentially covered: the frailty and limitations of the human body. One of the most ancient and

/pp 9-10/

widespread theories of technology --and the media, of course, are part and parcel of modern technology in general-- (one of the most ancient theories) construes technology as supplement of the body, a supplement to the physical limitations of human beings. In this view, technology should be understood as a kind of "prosthesis", as a device intended to compensate for shortcomings of the human body. If this is so, then it would explain why technology has long been regarded with deep ambivalence and misgivings: in helping to compensate for physical shortcomings, it also inevitably confirms such frailties and indeed implicitly at least calls attention to them. The greatest and most fundamental of such frailties is, of course, death itself. Another such frailty is the vulnerability of the body to external shocks.

It is surely no accident that in the example I have cited, what we are shown is a building, and more exactly, a concrete wall. It is the most aseptic kind of target: the ugly wall is suggestive more of a barrier, to our sight, for example, than of a shelter that might house people more or less like ourselves. But it is a very symptomatic barrier: we want to see more, and yet were we to see more, we might react very differently. The wall of the target that we see on our TV screens is itself a screen: it prevents us from seeing human bodies, faces, limbs and what happens to them when they are subjected to the same sort of military-televisual "scrutiny" of which we have so far been partial witnesses. Since much has been said already, in the media themselves, about the antiseptic nature of the reporting of this way, I will not belabor this point, except to suggest that such an antiseptic reporting may have something to do with the "prosthetic" aspect of media technology as such and in general. At the same time, where there is a prosthesis, there is inevitably a reference to physical frailty, to vulnerability, and to death itself. This is one reason why the media can be both reassuring, but also anxiety-producing. And also, why it is habit-forming: like 
crackerjacks, the more you see, the more you want. The more you are reassured, the more anxious you become. This is also why, on the rare occasions when such anxiety is addressed directly, it is almost a relief to see and to hear.

/pp 10-11/

But there is one further point I would like to draw out from the televisual bomb scenario. I would go so far as to suggest that it embodies a fundamental way of looking at the world, and of conceiving reality. Referring to a word that emerged in the pre-war dispute between the United States and Iraq, I would call it the attitude of non-linkage. Nothing is "linked" to anything else: except, that is, as a missile is "linked" to its target, by the trajectory of a straight line. There is the target, fixed between the cross hairs of the site. And there is the missile, homing in on that site. There is no further context visible, except that which reappears after the site is destroyed, or has vanished, and which is that provided by the media. The only "context" there is that of the media network. But the media network in turn consists largely in the atomizing "targeting" of isolated objects: faces, names, silhouettes. This is a war of the United States against Saddam Hussein. It is not a war against the people of Iraq, nor against the people of the Middle East, even if hundreds of thousands of them may well be killed and maimed in the weeks and months to come. And since this is essentially a war against the moral malignancy of a single individual, there is absolutely no need to report anything about the party which that individual leads, nor about the policies of his government, except insofar as they illustrate the personal malignancy of its leader. There is no need to discuss the history of Iraq, the social and economic policies of the government of Saddam Hussein, there is no need to discuss the economic pressures and their significance, as they affect all the participants in this conflict; no need to discuss the history of the region, the history of Kuwait, for instance, its social, political and economic policies. No need to discuss the question of the Palestinians. Such discussions are almost entirely absent from the mass media, since the outbreak of the war at least, and where they are aired, the time constraints of the national and international networks prevent any serious discussion from taking place. Here too the image of the bomb homing in on its target shows why: communication in the media must be kept short and decisive: sound-bites and sight-bites. "Please be brief", is the admonition that the journalists address at their invited guests: the only responses that are /pp 11-12/

tolerated are those that can be made in a sentence or two, or better, in a single word: Yes or No. And above all, no linkage: no complexity, no ambivalence, nothing that cannot be immediately visualized or immediately understood.

The underlying model of reality that such a reduction of discourse implies is a world of simple, straightforward choices and decisions. A world of either/ or, of Good versus Evil, of Power vs Impotence. Targeting and destroying an 
object is one expression of this attitude. Another is the sporting event: you have two, clearly distinct adversaries, they engage each other, and before too long there is a final decision, with a winner and a loser. In terms of the contents of what it displays, the media as we know it is increasingly committed to such an either/or, winner take all representation of reality. At the same time, however, the reality of the media itself, which includes the experiences of those who are its "end-users", is far less clear-cut. And nowhere is that more powerful than in that "live coverage" which today, more obviously than ever before, is "covering" death: that is concealing it and bringing it ever closer to all of us.

(January 24,1991)

\section{Shaping the Enemy :}

One of the lessons that can already be drawn from the Gulf war concerns the role that technology is called upon to play in the New World Order that the United States is seeking to establish in the wake of the Cold War. The astonishingly rapid ground war and the massive defeat of an Iraqi army of several hundred thousand men testifies to the decisive importance of technology in conventional military combat. As one commentator put it, "Victory is a property of the wealthy. Battles may be won by a David, but the Goliaths win the war," (James F. Dunnigan, cited in the LA Times, 2-27-91, A18). But the strategic significance of technology cannot be limited to its strictly military use: its political exploitation is at least as decisive.

/pp 12-13/

What is technology? One traditional view is that it evolves as a supplement to the physical capacities of human beings. Upon repeated occasions, American generals defined their overall strategy as that of rendering the enemy "blind and deaf", in order then to "kill" him: "When we knew that he couldn't see us anymore, we did a massive movement of troops all the way out to the west..." (N. Schwarzkopf, LA Times, 2-28-91, A10). Technology allowed one side to see and hear, and prevented the other side from doing the same. But preventing the other side from seeing and hearing does not just mean taking away the ability to perceive: it can also involve the use of technology to provide misleading sights. And it is here, interestingly enough, that the media makes its appearance in General Schwarzkopf's February 27th briefing, generally qualified by media observers as a "brilliant performance" (Anthony Cordesman and Ted Koppel on ABC): "Schwarzkopf, the commander of allied forces, exuded satisfaction at apparently having fooled the Iraqis into expecting a frontal offensive over the Saudi-Kuwaiti border. And he teased the press for its inadvertent role in it. Information on fake amphibious landing, Imminent Thunder, was leaked to reporters -- and extensively reported on-- to make the Iraqis fortify their position on the eastern shores of Kuwait. In fact, the brunt of the allied offensive would come on a far-western flank," (LA Times, 2-28-91, A6) 
This use of the press and the media generally to provide disinformation is a relatively simple and familiar one. A far more complex case, however, than that of "shaping the batttlefield" was that of shaping the political terrain upon which the conflict was waged. It is here that the task of defining, or "representing" the enemy fell to the media. It is here that the "perceptions" of the public were shaped.

What does it mean to "shape" perceptions? To address this question, we must first reflect for a moment on what is involved in "perception" itself. We usually think in terms of oppositions: we either see something, or we don't. The case of the simulated

/pp 13-14/

amphibious assault indicates that things are more complex: we can see something, but what we see is something different from what appears, i.e. from what we take that which appears to be. To perceive is not merely to see something in and of itself: it is to see something in relation to other things, in a context if you will. To perceive is to interpret, and to interpret is inevitably to choose and select certain relations, and to exclude and ignore others. In ordinary thought, this is related to the phenomenon of "concentration". When we concentrate on something, we do so only by selecting a certain set of items at the expense of others. Only so are we able to construct a "center": that is, by selectively determining what it is to be surrounded by, the "con-" in "con-centration". Were there no "surroundings" there would be no "center", and we would be unable to "concentrate", or, to translate this into visual language, we would be unable to "focus". In order to focus or to concentrate upon something, we must therefore "forget" the process by which the context or environment is delimited and determined. This is absolutely inevitable: were we not to "forget" the exclusions necessary to the demarcation of a field, within which an object is determined, nothing could be "seen" or identified. At the same time, to "forget" such exclusions is not simply to remove them once and for all: they remain, qua excluded, since without them the borders of the perceptual field, and hence of everything that becomes visible within it, would dissolve. The field of the visible is, therefore, paradoxically held together by that which is invisible.

This is why Freud is able to compare the phenomenon of "concentration", which he stresses, is an indispensable operation of normal thought, with what he calls the defense mechanism of "isolation". Isolation accomplishes the same task as repression, but in a more subtle way: whereas in repression a painful idea is removed from consciousness and replaced by another, more acceptable one (which retains however a relation to the repressed idea), isolation does not remove the unacceptable idea: it simply "isolates" it from its consequences and ramifications, thus rendering it relatively harmless. The fact that a neurotic defense mechanism such as isolation should bear such affinity to a normal intellectual 
operation such as concentration suggests that normal thought may be no less subject to unresolvable contradictions than is neurosis. If there is a difference between the two, it can only relate to the way in which the exclusions are practiced, not to the fact of exclusion itself. Translated into the language of visual perception, one such difference would be the way in which a perceptual field, and the phenomena that take place within it, are interpreted (i.e. perceived): they may be taken as simply self-identical, which means, as a correlative, that the field in which they appear is taken for granted; or the "focus" of attention can shift from the object, or the center, toward the margins of the field itself: instead of its being taken for granted, the process of "granting" itself can become a subject of inquiry. However, there is no entirely satisfactory resolution of this problem: if the center depends upon its surroundings, which in turn depend upon what they exclude, the latter can never be fully grasped or perceived, since each new shift in attention merely reconstitutes a new set of borders and exclusions. What can change, however, is the way perception and interpretation themselves are experienced and practiced: the unproblematic focus upon a center of attention can shift to a kind of scanning in which the peripheries are no less significant than the center, even if those peripheries can never be as exhaustively and definitively identified as one might believe, erroneously, would be the case for the center.

What does all this have to do with the representation of an enemy through the media? Quite a bit. The media, and particularly television, at least as we know it, favor the kind of concentrated focus just discussed. They favor it spatially as well as temporally. Television encourages a conception of reality consisting of self-contained images and discrete events. It discourages reflection upon the relations, or environment, that allow images and events to take place. In discouraging such reflection, television itself steps in to assume the role of determining context: the network, spanning the world with its eyes and hears, presents events as they happen, and if possible, "live". Such "live coverage" winds up "covering" death: death becomes the invisible end of a life that is sundered from the others that endow it with meaning and identity. Death is the /pp 15-16/

unnameable name of the game. "BDA" --Bomb Damage Assessment is an "art", not a science, the generals insist, in refusing to provide figures for the deaths they are causing. Bombs, guided by television cameras, send back images of their flight, which culminates in the penetration of the object targeted and in the ensuing disappearance of its image. The viewer is confronted first with a dark screen, highlighted by a thousand points of light (but no image, no figure, no object), and then returned to the network anchorman and/or woman, against the backdrop of the thousand watchful eyes of the network control room.

What now of the shaping of the enemy through the representations of the media? But first: What is an enemy? Hegel defines the enemy as a "negated 
otherness" (C. Schmitt, The Concept of the Political, p. 63). What, in this case, does it mean to negate the "otherness" of Iraq, so as to define it as the enemy? First of all, it means excluding Iraq from the "family" or "community" of law-abiding nations, by detemining it, literally, as an out-law. The universal validity of the law that forbids one sovereign nation from invading another can be taken for granted all the more easily in one specific case, insofar as its consistent violation in other equally specific cases, by those who invoke it this time, is excluded from consideration. The universal validity of the law that prohihits one nation from occupying the lands of another can be invoked all the more categorically in this particular case inasmuch as other equally particular cases are explicitly ignored. In short, the universality of laws and the validity of resolutions are taken for granted in one case by ignoring and indeed negating other cases in which these same laws and resolutions have been violated. "No linkage" and "no negotiations" is the battle-cry of this new universalism. Everything is to be taken in isolation from everything else: law is law, resolutions are resolutions, an invasion is an invasion, and nothing more. How, precisely, does this isolation work in the media to shape the enemy?

It take place in at least two ways. First, the political expression of a country, Iraq, is reduced to a single individual, who

\section{/pp 16-17/}

can be identified and judged, unequivocally and unambiguously, through the invocation of a proper name: "Saddam Hussein". Iraq, the outlaw, is Saddam Hussein and Saddam Hussein is the political manifestation of Iraq. The enemy is thus given a human face and a proper name, and both become the exclusive focus of attention. The enemy is thus endowed with a face and a name, it is shaped into a he, an individual man subject to instant recognition when represented on television or when mentioned in the media. The question then becomes: what or rather who is Saddam Hussein? The answer is not long in coming: He is, above all, a "thug", a lowly but aggressive criminal who lives by violence and, by implication, will die by it. A very apt caricature in the LA Times of Feb. 27 is entitled face: it shows a faceless figure in military uniform, apparently Saddam Hussein stripped of face and name. The "negated other", one might say. Except -- except that the negation that turns the other into the enemy has already long since taken place: it is not the stripping of face and name that constitutes the enemy as the negated other, but rather the giving of face and name : by giving Iraq the face and name of Saddam Hussein, all the impersonal relations that help to make up a political entity are already negated, or rather excluded. Despite the fact that constant coverage of the Gulf crisis and war left the networks scrounging for material, I cannot recall a single discussion or even mention of the social and economic policies pursued by the Ba'athist party in Iraq since it acceded to power in 1968. Not a word about education, health care, housing, not a word about distribution of wealth or the situation of women in Iraq (nor for that matter in Kuwait or Saudi Arabia, where, admittedly, such is taken for granted). Not a word about the financial pressures brought to bear upon Iraq nor about the history and details of its dispute with Kuwait. Rare mention and no discussion of the behavior of U.S. Ambassador April 
Glaspie when she assured Saddam Hussein, in a meeting with him on July 25th, that "We have no opinion on the Arab-Arab conflicts, like your border disagreement with Kuwait" (J. Miller and L. Mylroie, Saddam Hussein and the Crisis in the Gulf, p. 18). And in general, practically no mention or discussion of the various policy scenarios defining possible American policies toward the Gulf.

/pp 17-18/

Such exclusions are indispensable in allowing the enemy to take shape, and indeed, to assume the face, the name and above all, the characteristics of a single individual: ruthless, quixotic, ambitious, and above all: simply and malignantly evil. Such exclusions enable television viewers to focus upon the enemy as an object of moral condemnation: political complexities are reduced to the choice between good and evil, peace and war, legitimacy and agression. And it is this choice, in turn, that justifies one of the most massive and most destructive military operations since the Second World War. The media, and in particular, television, lends itself to such reductions by its formal structure, which is both technologically and economically determined. The impossibility, in a privately organized television network, to allot substantial periods of time for discussion, the tendency to present discourse as short "sound-bites", effectively excludes the airing of complexities, thus contributing to that "negating of the other" by which the "enemy" is shaped: that is, given face and name. Once thus endowed, the purpose of the war can be presented as that of depriving Saddam Hussein of his power, and ultimately, causing him to lose face. It is this war-aim that the LA Times caricature confirmed.

At the same time, new faces emerge on the screen, those of surrendering Iraqi soldiers, shown at first stripped from the waist, then in countless lines and groups. These are the nameless faces of the enemy, the negated other, without any unity other than that of surrendering prisoners of war. Many of them, we read in the newspapers, do not want to return to Iraq: they want to come to the United States. Now that Iraq has lost its 19th province, perhaps it can aspire that one day it might become the 51st state...

The final negation of the other thus moves into view. On CNN the show has changed its name from "War in the Gulf" to "Peace in the Gulf", accompanied by a new and appropriately victorious fanfare. We can begin the business of forgetting the enemy, it suggests, and instead resume that of focusing again on our friends... The Kuwaitis and Saudis rejoice and their joy is placed /pp 18-19/

center stage. But on the margins, in Jordan and Yemen, Algeria, Marocco and Pakistan other sounds are heard. The show goes on, but the story is far from over. 
University of California

Los Angeles - CA 90024 - USA

$/ \mathrm{p} 19 /$

Surface Page d'Acceuil/Home Page 